\title{
Adiposity in childhood cancer survivors: insights into obesity physiopathology
}

\author{
Adiposidade em pacientes tratados por câncer na \\ infância: entendendo a fisiopatologia da obesidade
}

Adriana Aparecida Siviero-Miachon', Angela Maria

Spinola-Castro', Gil Guerra-Junior ${ }^{2}$

Departamento de Pediatria,

Divisão de Endocrinologia

Pediátrica, Universidade

Federal de São Paulo (Unifesp/

EPM), São Paulo, SP, Brasil

${ }^{2}$ Departamento de Pediatria,

Divisão de Endocrinologia Pediátrica,

Faculdade de Ciências Médicas

da Universidade Estadual de

Campinas (FCM-Unicamp),

Campinas, SP, Brasil

\begin{abstract}
As childhood cancer treatment has become more effective, survival rates have improved, and a number of complications have been described while many of these patients reach adulthood. Obesity is a well-recognized late effect, and its metabolic effects may lead to cardiovascular disease. Currently, studies concerning overweight have focused on acute lymphocytic leukemia and brain tumors, since they are at risk for hypothalamic-pituitary axis damage secondary to cancer therapies (cranial irradiation, chemotherapy, and brain surgery) or to primary tumor location. Obesity and cancer have metabolic syndrome features in common. Thus, it remains controversial if overweight is a cause or consequence of cancer, and to date additional mechanisms involving adipose tissue and hypothalamic derangements have been considered, comprising premature adiposity rebound, hyperinsulinemia, leptin regulation, and the role of peroxisome proliferator-activated receptor $\gamma$. Overall, further research is still necessary to better understand the relationship between adipogenesis and hypothalamic control deregulation following cancer therapy. Arq Bras Endocrinol Metab. 2009;53(2):190-200.
\end{abstract}

Keywords

Adiposity; precursor cell lymphoblastic leukemia-lymphoma; brain neoplasms; radiotherapy; drug therapy; leptin

\section{RESUMO}

Os avanços do tratamento contra o câncer infantil têm resultado no aumento da sobrevida e das complicações, à medida que os pacientes atingem a maioridade. A obesidade é um evento reconhecido, e seus efeitos metabólicos levam à doença cardiovascular. Atualmente, o estudo da obesidade tem enfocado a leucemia linfocítica aguda e os tumores cerebrais, já que ambos têm risco para lesões hipotalâmicas, secundárias às terapias (irradiação cranial, quimioterapia, e cirurgia) ou à localização do tumor. Obesidade e câncer têm em comum fatores para síndrome metabólica. Entretanto, a relação de causa e efeito entre obesidade e câncer permanece controversa, sendo que são considerados outros mecanismos envolvendo o tecido adiposo e lesões hipotalâmicas, como o rebote precoce de adiposidade, hiperinsulinemia, regulação da leptina, e o papel do receptor ativado por proliferadores de peroxissoma $\gamma$. Concluindo, mais estudos são necessários para entender a relação entre adipogênese e descontrole hipotalâmico em sobreviventes de câncer. Arq Bras Endocrinol Metab. 2009;53(2):190-200.

Received in Jan/07/2009

Accepted in Feb/03/2009

\section{Descritores}

Adiposidade; leucemia-linfoma linfoblástico de células precursoras; neoplasias encefálicas; radioterapia; quimioterapia; leptina

I the last twenty years, as treatment became more effective in curing children with cancer, survival rates have improved greatly, and while many of these patients reach adulthood, a significant number of long-term com- plications (late effects with long-term medical implications) have been described. Obesity is a well-recognized late effect, and there is currently considerable concern about the metabolic/endocrine effects leading to im- 
portant implications for long-term survivors, as accelerated weight gain is associated with increased morbidity and mortality, particularly due to cardiovascular disease (CVD). Moreover, social, psychological, and economic consequences also require attention (1).

The new paradigm for defining successful cancer therapy is the balance between drug efficacy and toxicity/late effects. Survivors of some pediatric cancer groups, particularly acute lymphocytic leukemia (ALL), brain tumors, sarcomas, lymphomas, disseminated testicular cancer, neuroblastomas, Wilms tumor, and following bone marrow transplantation (BMT), are recognized to present clinical features of the metabolic syndrome (MetS), and therefore increased risk factors for CVD, such as visceral obesity, insulin resistance (IR), glucose intolerance, dyslipidemia, arterial hypertension, and endothelial dysfunction (1-9).

Currently, research on overweight/obesity in childhood cancer survivors has focused mostly on survivors of ALL or brain tumors, which have become important disease models giving us clues for a better understanding of the metabolic disturbances, and some of the mechanisms of weight gain among cancer survivors. This population is considered at particular risk since cranial radiation therapy (RT), surgery, or the tumor itself can damage the hypothalamic-pituitary axis. Direct damage to the satiety center in the ventromedial nucleus of the hypothalamus, leptin insensitivity, growth hormone $(\mathrm{GH})$ deficiency, chemotherapy (CT), including glucocorticoids and alkylant drugs, and psychosocial problems, have all been pointed out as additional mechanisms implicated in the pathogenesis of obesity (10-20).

The aim of this review is to discuss the main pediatric groups at risk for developing obesity after a successful cancer treatment, the predisposing factors, and the most accepted mechanisms related to weight gain in this particular population.

\section{OBESITY AND ITS ROLE IN CANCER}

Obesity is a multifactorial disorder influenced by genetic, behavioral, environmental, and cultural factors. Recently, studies have showed that obesity in adult life is heralded at birth, and factors such as birth weight, adiposity rebound, socioeconomic status, early maturation, genetic predisposition, sex, and ethnicity/race may have a significant effect on the propensity to develop obesity from childhood to adulthood $(21,22)$.
Cancer and chronic diseases could possibly be connected through a variety of risk factors for metabolic disease that both conditions may have in common, such as visceral obesity, hyperinsulinemia, and IR. In addition, the association between visceral obesity, type 2 diabetes mellitus (T2DM), and cancer, incite speculations about the mechanisms linking adiposity and IR, and resulting in the occurrence of certain types of cancer. Visceral obesity has been recognized as a risk factor for the development of the so-called "obesity-related cancers", encompassing breast (post-menopausal), endometrial, colorectal, and pancreatic carcinomas, as well as for other malignancies, such as leukemia, multiple myeloma, and non-Hodgkin's lymphoma $(20,23)$.

Nevertheless, mechanisms underlying the association between adiposity and cancer still remain unexplained, and are only starting to be understood. On the other hand, it is highly controversial if carcinogenesis itself could possibly contribute to the development of obesity and MetS as well, in survivors of various malignancies. Carcinogenesis is multifactorial and depends not only on metabolic disturbances but also on the inherited genetic background $(20,23,24)$.

Thus far, insulin-growth factor (IGF)-1 secretion has been associated with patterns of childhood growth, as well as adult stature and adiposity, suggesting that IGFs may contribute to a number of anthropometric associations with cancer risk (25). Recently, some molecular mechanisms by which insulin (closely related to IGF) and its tyrosine kynase receptors (closely related to IGF-1 receptors) play a role in cancer biology have been elucidated. Insulin receptors are over-expressed in several human malignancies and in conjunction with IGF-1 receptors may contribute to the formation of hybrid receptors. Consequently, by binding to these receptors, insulin stimulates specific signaling pathways related to IGF-1. So far, all these receptors, insulin, IGF-1, and hybrid receptors, are the major targets for novel anticancer therapies. Additionally, specific polymorphisms in certain genes encoding proteins involved in the IGF signaling pathway, including IGF-1 itself, are associated with a variation in cancer risk $(20,23,24,26-28)$.

Overall, along with the neoplastic disease itself that probably causes changes on inflammatory mediators, and adipokines (leptin and adiponectin), as well as interferes with insulin sensitivity and lipid metabolism, considerable metabolic derangements may be aggravated by anticancer therapies, including CT and RT $(20,26)$. 


\section{FROM ADIPOGENESIS TO ONCOGENESIS}

\section{Adipogenesis}

Adipocytes originate from multipotential mesenchymal stem cells derived from the adipose tissue stroma. Adipogenesis can be divided into two phases: determination, which results in the conversion of the stem cell into a preadipocyte and terminal differentiation, in which a preadipocyte takes on the characteristics of the mature adipocytes and acquires the machinery that is necessary for lipid transport and synthesis, insulin sensitivity, and the secretion of the adipocyte-specific proteins. Nonetheless, it has been difficult to characterize the factors that lead pluripotential cells to preadipocytes, and thus to mature adipocyte lineage, or to describe distinct cellular intermediates. It is likely that paracrine signals released from fat cells trigger the initiation of preadipocyte differentiation into mature fat cells (29).

Adipocyte differentiation involves a temporarily regulated set of gene expressed events, which require a crucial nuclear transcription factor, the so-called peroxisome proliferator-activated receptor $\gamma(\operatorname{PPAR} \gamma)$, also responsible for the maintenance of the adipocyte phenotype. Furthermore, adipocyte differentiation is also influenced by the balance of different signals, pro and anti-differentiation, which are provided by locally produced growth factors, cytokines, and circulating hormones, and can also exert an important influence upon adipocytes. Insulin and IGF-1 stimulate, directly or indirectly, proliferation of preadipocytes and increase expression of PPAR $\gamma$. In addition, glucocorticoids also stimulate other transcription factors that play a role in adipocyte differentiation. Therefore, chronic excess of glucocorticoid produces increased body fat. On the other hand, GH stimulates preadipocyte differentiation to mature adipocytes and limits fat storage $(29,30)$. After ALL and brain tumor therapy, many survivors may develop $\mathrm{GH}$ deficiency, which will be further discussed in another section (Figure 1).

Moreover, adipocytes express the enzyme $11 \beta$ hydroxysteroid dehydrogenase type 1 , which catalyses the reduction of the inactive steroid (cortisone) into the active hormone cortisol. The expression of this enzyme is upregulated in differentiated adipocytes and is increased in visceral fat compared with subcutaneous

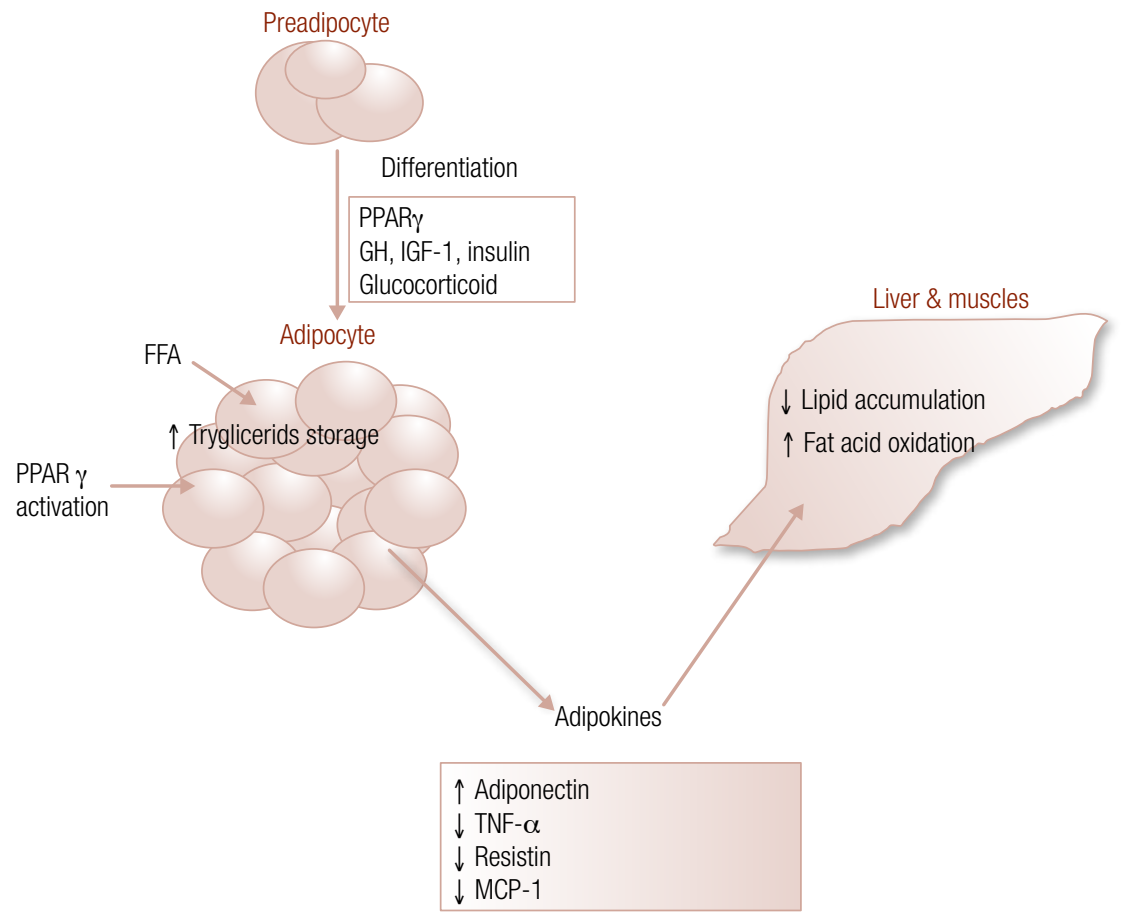

PPAR $\gamma=$ peroxisome proliferator-activated receptor $\gamma$, GH = growth hormone; IGF-1 = insulin-like growth factor-1; FFA = fat free acids; TNF- $\alpha=$ tumor necrosis factor-alpha; MCP-1 = monocyte chemoattractant protein-1.

Figure 1. The role of PPAR $\gamma$ in adipocyte differentiation and activation.

PPAR yactivation by biological or synthetic ligands alters insulin sensitivity by regulating adipokine production (increased adiponectin, and decreased TNF- $\alpha$ and resistin levels), as well as lipid storage (FFA accumulation and increased tryglicerides). This process results in decreased FFA flux to systemic circulation, as well as reduced lipid accumulation, and increased fat acid oxidation by liver and muscles, contributing to the state of enhanced insulin sensitivity (Adapted from reference 30). 
fat, which may contribute to the preferential deposition of fat viscerally, rather than subcutaneously, in states of cortisol excess (29). This could possibly explain the altered body fat composition, and distribution as well, during and after ALL treatment, which comprises high doses of glucocorticoids, particularly during the first 4 weeks of therapy.

\section{Peroxisome proliferator-activated receptor $\gamma$ (PPAR $\gamma)$ : "master" regulator of adipogenesis}

The adipocyte acts as an endocrine organ. Adipose tissue is controlled by several signals, including PPAR $\gamma$, which belongs to the family of nuclear hormone receptors, and is the dominant or "master" regulator of adipogenesis. In response to these signals, mature adipocytes secrete inflammatory mediators and adipokines, which control endothelial function, atherogenesis, energy balance, and also activate intracellular pathways, regulating the subacute inflammatory state associated with obesity, and the development of IR and T2DM. Adipokines and inflammatory mediators comprise leptin, adiponectin, resistin, visfatin, estrogen, interleukins, angiotensinogen, lipoprotein lipase, $11 \beta$-hydroxysteroid dehydrogenase type 1 , monocyte chemoattractant protein- 1 (MCP-1), tumor necrosis factor-alpha (TNF- $\alpha$ ), C-reactive protein (CPR), and plasminogen activator inhibitor (PAI-1) (31). Adiponectin is an adipokine inversely correlated with adipose tissue and, in turn, to IR. On the other hand, TNF- $\alpha$ and resistin are directly associated with IR (30).

The identity of the natural and synthetic ligands for PPAR $\gamma$ remains unresolved, and is an area of active investigation. Several studies have showed that long-chain polyunsaturated fatty acids and related molecules are the biological ligands for PPAR $\gamma$, which is also the biologic receptor for the thiazolidinedione (TDZ) antidiabetic drugs currently in widespread use for the treatment of T2DM. PPAR $\gamma$ has a central role in the promotion of adipogenesis and its activation in the adipose tissue improves whole-body insulin sensitivity through a combination of metabolic actions, including partitioning of lipid stores and the regulation of adipokine production, comprising increase in adiponectin levels and decreased production of TNF- $\alpha$ and resistin. Multiple studies have showed that deletion of PPAR $\gamma$ in mature adipocytes compromises their viability and leads to lipodystrophy and IR (30) (Figure 1).

\section{PPAR $\gamma$ : further than fat}

The ability of PPAR $\gamma$ to direct the program of adipocyte differentiation, characterized by a complete cessation of cell growth, was a stimulus to examine the capacity of this receptor to interfere with tumor growth. The concentration of PPAR $\gamma$ is increased in adipose cells, but a substantial amount is also present in certain other cell types, such as the colonic epithelium, and epithelial cells of the breast and prostate. Application of PPAR $\gamma$ ligands showing an antigrowth and/or pro-differentiation response have now been reported for a huge variety of cancer cells, including those derived from colon, lung, ovary, breast, thyroid, and prostate cells (30).

To date, PPAR $\gamma$ signaling has also been implicated in the control of atherosclerosis, macrophage function, immunity, and inflammatory response, but no consensus has been reached regarding how PPAR $\gamma$ activation alters cell growth. Therefore, genetic studies in mice have elucidated that the loss of even one allele of the PPAR $\gamma$ gene predisposes to cancer. Thus, in the genetic sense, PPAR $\gamma$ must be formally considered a tumor suppressor gene (30).

PPAR $\gamma$ ligands have been utilized in a therapeutic context as a monotherapy in several advanced forms of human cancer, including prostate, breast, and colon cancer. In addition, PPAR $\gamma$ agonists have recently been combined with a number of more classical chemotherapeutic agents (comprising platins). Overall, it has remarkable antineoplastic effects both in solid cancer and leukemia through inhibition of cell proliferation, induction of apoptosis, and terminal differentiation, as well as inhibiting angiogenesis $(30,32)$.

All the factors implicated, directly or indirectly, in adipogenesis, comprising the adiposity signals (particularly PPAR $\gamma$ and insulin), adipokines, as well as the hypothalamic control of the appetite, may be profoundly damaged by cancer itself throughout diverse pathways, or by the different drugs and treatments necessary to reach the cure. To date, there is almost no research available concerning the cellular mechanisms of adipogenesis after cancer treatment. Thus, the link between PPAR $\gamma$, oncogenesis, adipogenesis, and the major role of a variety of factors that could possibly explain adipogenesis deregulation in cancer survivors still remains to be established (30).

\section{UNDERLYING MECHANISMS FOR OBESITY IN PEDIATRIC CANCER GROUPS}

Regarding adiposity in childhood cancer survivors, two types of cancer are of major interest: ALL and brain 
tumors. They both have in common cranial RT administration, which is one of the important factors implicated in obesity physiopathology among cancer survivors. Nonetheless, other mechanisms, not fully understood yet, have been hypothesized, so both types of cancer are considered diverse models for comprehending obesity/overweight, as well as its resulting metabolic derangements (10-20,33-39).

The more conventional and frequently used methods to assess the relative metabolic load or risk imposed by fatness in childhood cancer survivors are body mass in$\operatorname{dex}(\mathrm{BMI})$, skinfold thickness, electrical bioimpedence, and the dual energy $x$-ray absorptiometry (DEXA), acknowledged as the gold-standard (6,11-16,40).

Currently, clinical screening tools, waist circumference (WC) and waist to hip ratio, rather than BMI, have been suggested in MetS definition criteria both in pediatric and adult patients, as they better evaluate changes in body fat distribution, predominant in childhood cancer survivors, in place of body composition $(41,42)$. In addition, another relation, the so-called waist to height ratio, has been positively correlated with visceral adipose tissue (VAT), particularly when it is greater than 0.5 , even in post-malignancy treated subjects (5). Thus far, central or abdominal adiposity is assessed using computed tomography $(\mathrm{CT})$ or magnetic resonance imaging (MRI) scans at the L4-L5 level $(6,43)$.

The principal mechanisms involved in weight gain in ALL, and in brain tumor survivors, are summarized in Table 1 , and are further discussed in the following sections.

\section{ACUTE LYMPHOCYTIC LEUKEMIA}

\section{Growth hormone deficiency: role of radiotherapy (and chemotherapy)}

Weight gain is either a short or a long-term effect of ALL therapy. Weight increases and body composition changes during the first 4 weeks of therapy due to glucocorticoid administration, encompassing prednisone or dexamethasone. During this phase, height decreases, probably as a result of a partial and transient GH insufficiency or insensitivity (16), and linear growth might be followed or not by catch-up growth during the maintenance therapy $(14,16)$. A number of ALL survivors, regardless of their adequate weight gain, may become overweight for height, due to their relative height loss, which is very usual after cranial RT, especially when administered at a young age, but that may also occur in CT only treated patients $(14,33)$. GH deficiency is the
Table 1. Primary mechanisms for overweight/obesity in acute lymphocytic leukemia and brain tumor survivors (10-20,33-39)

\section{Acute lymphocytic leukemia}

Growth hormone deficiency/Hypothalamic damage (due to):

Cranial radiation therapy (12-24 Gy)

Chemotherapy (less frequent)

Leptin deregulation

Premature adiposity rebound

Other mechanisms:

Familial background

Poor dietary choices

Increased sedentary behavior

Reduced physical activity

\section{Brain tumors - hypothalamic obesity}

Growth hormone deficiency/Hypothalamic damage (due to):

Tumor itself

Cranial (or craniospinal) radiation therapy (> 45-51 Gy)

Radical resection

Intratumoral therapy (bleomycin and/or interferon- $\alpha$ )

Chemotherapy (less frequent)

Other mechanisms:

Vagally mediated hyperinsulinemia (autonomic imbalance)

Lack of sensitivity to endogenous leptin

Reduced physical activity

most frequent endocrine dysfunction observed following cranial RT. GH is implicated not only in growth regulation, but also in metabolism. GH deficiency frequently induces MetS-like disorders, such as visceral obesity, hypertriglyceridemia, low HDL-cholesterol, coagulopathy, and hypertension (20).

On the other hand, accelerated weight gain, rather than height loss, has also been observed in ALL survivors, particularly during the first two years after therapy withdrawal (16). However, the real role played by weight gain in BMI increase after cancer therapy is not wellestablished, because almost all the data available from the Childhood Cancer Survivor Study (CCSS), the largest study on cancer late effects in the U.S. population, as well as other studies concerning weight gain in ALL survivors, have focused strictly on BMI, so there are few data on weight or height evolution (11-16,33,34).

Excessive weight gain during ALL treatment has usually been related to steroid adverse effects and disturbances on appetite regulation, depending on central nervous system treatment, as well as less energy expenditure due to physical inactivity. Nevertheless, these factors do not fully explain overweight in this group of patients and influences of corticosteroid treatment and cytostatics on body composition are still uncertain $(14,15)$. 
There is a well-established association between obesity and cranial RT (10). Among female survivors of ALL and brain tumors, especially if treated with cranial RT, the prevalence of obesity is increased if compared with the general population while survivors of other malignancies are frequently underweight (15). On the basis of the CCSS data, ALL survivors who have received more than 20 Gy cranial RT (frequently 24 Gy) were at increased risk of overweight/obesity, especially females, and those treated before the age of five $(11,12)$. Furthermore, other studies not only confirmed the impact of RT on weight gain, but also evidenced a sexually dimorphic and dosedependent effect of radiation on the human brain, proving that sex and age are important determinants of obesity in ALL survivors (13). Cranial RT has also been strongly related to GH deficiency, and in turn to lower IGF-1, raised leptin and fasting insulin concentrations, altered body fat distribution (abdominal obesity), and dyslipidemia in both sexes, but particularly in women $(4,6,40)$. In addition, female ALL survivors have less lean mass and VAT, but higher total adipose tissue (TAT) and subcutaneous adipose tissue (SAT) than males (6). Changes in BMI are usually greater in the 24 Gy irradiated group compared with the 18 Gy sample, confirming the dose-dependent effect of cranial RT (13) (Figure 2).

On the other hand, a large amount of childhood ALL survivors have not been treated with cranial RT, or received low radiation doses (between 12 and 18 Gy). However, some of them have developed obesity, MetS

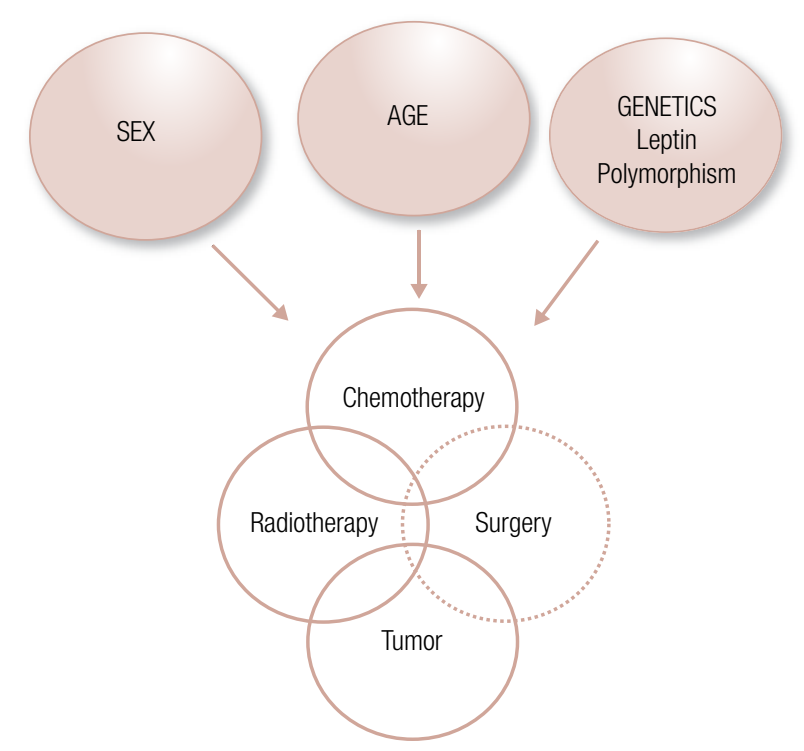

Figure 2. Interaction between individual host characteristics and cancer therapy in determining overweight/obesity in childhood cancer survivors (Data from references 11 and 37). traits, and GH deficiency as well (44). Whether CT only or low-dose cranial RT is related to the development of obesity is controversial and a matter of discussion. Nevertheless, it has been greatly reported by various previous statements $(14,16,35)$. In these studies CT composed mainly by glucocorticoid was shown to decrease fat oxidation during fasting and to produce a significant increase in weight gain right after the beginning of the therapy and at the end of it (45). Thus far, while CT itself predisposes to obesity and features of MetS in ALL survivors, once in combination with cranial RT this effect may be intensified $(1,3,4,6,8,40,46)$.

Nonetheless, in substantial disagreement with previous studies (11-15), a variety of statements $(18,36,45)$ did not find an increase in obesity/overweight in ALL survivors, in spite of cranial RT administration. The first study developed by our group (Sao Paulo, Brazil) found that weight and BMI transversally determined 3.4 years after ALL therapy withdrawal at a mean age of 11.5 years did not differ between irradiated compared with nonirradiated subjects, only one irradiated subject (24 Gy) presented with BMI standard deviation score $(\mathrm{SDS})>2.0$, and BMI SDS was similarly distributed according to the presence of cranial RT (18). Another study from Brasilia, Brazil, described a group of irradiated childhood ALL survivors (18-24 Gy) at a mean age of 14 years, who did not develop obesity at a mean 8 years after the end of CT. The authors justified this by explaining that patients came from lower economic classes of the Brazilian community, in which the diet is low-fat, and family overprotection of the sick child was probably poor (45). In addition, Nathan and colleagues also presented the results of a study of $\mathrm{Ca}^{-}$ nadian children and adolescent survivors of cancer (ALL, lymphomas, sarcomas, brain tumors, and others) in which the prevalence of overweight was not greater compared to the general population, but a substantial proportion of these pediatric patients were overweight, especially male survivors, which contrasts with the CCSS data (11), despite the presence of cranial RT (18 or 24 Gy) (36). All these studies supported that body weight also depends on the interaction between genetic background, sex, ethnicity/race, and environmental factors $(18,36,45)$.

\section{Leptin regulation: sex dimorphism and genetic susceptibility through polymorphism}

Leptin, a hormone encoded by the $O B$ gene and secreted mainly by adipocytes, regulates appetite and energy expenditure by acting in the hypothalamus $(18,47)$. 
Moreover, it is also known to play a role in leukemia physiopathology as its receptors, which are members of the cytokine receptor super family are expressed in leukemia blast cells $(18,48)$. Along with cranial RT and young age, genetic susceptibility through population leptin receptor polymorphism may contribute to BMI, and also influence obesity in female survivors of childhood ALL (37) (Figure 2).

Leptin regulation disorder and leptin resistance have been hypothesized to play a role in the development of obesity in ALL survivors. In addition, leptin itself is an important adiposity index during and after ALL therapy as it correlates significantly and positively with BMI (16-19), but not with age or dose of cranial RT or with markers of GH secretion $(17,18)$. Previous studies comparing nonirradiated ALL patients with those treated with cranial RT (12-24 Gy) have found either similar levels $(16,18)$ or even higher leptin concentrations in the irradiated group $(6,19,49)$. The pathophysiological significance of the hyperleptinaemia remains to be established, but it has occurred either as a consequence of radiation induced hypothalamic damage or GH deficiency (17-19). In addition to this, premature CVD has also been correlated with hyperleptinaemia and $\mathrm{GH}$ deficiency induced by cranial RT or CT only $(1,3,44)$.

Sex shows an important influence upon leptin levels and upon the relationship between BMI and leptin as well. Females tend to exhibit higher levels compared to males. Sexual dimorphism in leptin concentrations may be influenced by body fat distribution, therefore leptin correlates better with BMI and total body fat in females (50). However, strongest and positive correlation between leptin and BMI has been recently described by our group in males, even though there was no significant difference in leptin concentrations or BMI between sexes. Nonetheless, body fat distribution has not been evaluated in this study, so that the real influence of gender upon leptin, and consequently its role in body fat distribution, has not been clarified yet (18).

Leptin was considered an excellent nutritional marker and increased in ALL patients one year after CT withdrawal, independent of the presence of cranial RT. Along with the leptin increment, ALL patients tended to become obese (16). On the contrary, a current statement described by our group showed that nonirradiated ALL survivors tended to exhibit decreased leptin concentrations according to years elapsed since therapy withdrawal, but in irradiated ALL subjects serum leptin levels did not change as a function of time (18).

\section{Premature adiposity rebound}

The timing of adiposity rebound (AR) in childhood has been shown to have strong correlations with adult obesity. The AR is the period of childhood (typically between 5 and 7 years) when BMI and other indexes of adiposity begin to increase after reaching their nadir (35). Children with an earlier adiposity rebound were heavier and had above average BMIs. Early rebound is the result of higher rates of weight gain, measured in percentage terms, rather than slower than average accrual of stature. Low birth weight, and early rapid infancy growth is correlated with subsequent obesity risk in childhood and later life (51).

The so-called premature AR is an additional mechanism that might contribute to obesity in survivors of ALL (35), and a similar situation is observed in smallfor-gestational-age children (52), and congenital hypothyroidism subjects (53), who present drastic changes in body composition that have been suspected to favor the later development of the long-term metabolic complications by promoting central adiposity and IR during early childhood (51).

Considering that ALL occurs most often in preschool children aged between 3 and 5 years (and that physiological adiposity rebound would only occur between 5 and 7 years), there is an evident early rebound in these children, since CT administration comprising high doses of glucocorticoid, especially in the first 4 weeks of treatment, and cranial RT, may alter body fat composition and distribution still during treatment, as well as in the following years after therapy withdrawal $(6,16,40)$.

\section{Other factors}

Other possible contributing mechanisms to the development of overweight/obesity after ALL therapy are, as follows: familial background (38), poor dietary choices, increased sedentary behavior, and reduced physical activity (36).

\section{BRAIN TUMORS: A MODEL FOR HYPOTHALAMIC OBESITY}

Children with brain tumors are at an extremely high risk for the development of obesity after therapy, especially those with craniopharyngioma or following radical resection or cranial/craniospinal RT (medulloblastomas, astrocitomas, ependymomas, and nasopharynx 
carcinomas). Craniopharyngioma is the most common tumor of the hypothalamus-hyphophyseal region in childhood. To date, the tumor itself, and the possible approach including radical resection, intratumoral therapy (bleomycin or interferon- $\alpha$ ), and less frequently cranial RT, may result in severe neurological and endocrine sequelae. Craniopharyngioma surgery may also increase the risk of MetS still in childhood, including IR due to excess weight gain and GH deficiency (5456). Additionally, brain tumors receiving RT exceeding 45 Gy showed an altered body composition (2).

Brain tumor survivors with hypothalamic damage present a form of obesity termed "hypothalamic", with a weight gain often intractable, secondary to the tumor itself or to cancer therapy, not responsive to diet and exercise interventions, and commonly associated with other hormonal deficiencies (particularly GH deficiency). A very elegant retrospective analysis was performed by Lustig and colleagues in an attempt to identify, among children diagnosed and treated for primary brain tumor, the more important risk factors for obesity. Patients with spinal cord involvement or spinal cord RT were excluded from the study (due to the possibility of height loss), as well as patients receiving supraphysiologic doses of glucocorticoids. Rates of BMI increment were systematically evaluated and compared with that of the general American pediatric population, taking into account BMI curves. BMI change rates of brain tumor patients when compared with normal children were significantly different. No effect of ventriculoperitoneal shunting, steroid use or CT was noted (55). To date, the major risk factors that predict the development of obesity in brain tumor survivors were, as follows: hypothalamic location, extent of surgery, hypothalamic RT exceeding $51 \mathrm{~Gy}$, and the presence of hypothalamic-pituitary deficiencies, particularly GH deficiency $(55,56)$.

The existing statements concerning uncontrolled hyperphagia and hypothalamic obesity secondary to craniopharyngioma involve patients treated with either surgery or RT, and correlate findings to GH deficiency due to hypothalamic damage (54). Experimental studies have showed the relationship between hyperphagia, hyperinsulinism, and weight gain with lesions of the ventromedial hypothalamus $(\mathrm{VMH})$. Afferent vagal and hormonal (ghrelin, insulin, and leptin) signals are generated from the liver, gut, pancreas, and adipose tissue. These signals are interpreted in the VMH, and efferent signals from this area in turn stimulate either the sympathetic nervous system to expend energy by activating $\beta$-adrenergic receptors and enhance lipolysis (by adipocytes), heat and physical activity; or the parasympathetic nervous system (vagus nerve) to increase insulin secretion, with resultant adipogenesis and energy storage. When a lesion of the VMH occurs (due to the tumor itself, radical resection, intratumoral therapy or high-dose cranial RT), it results in dysregulation of pancreatic $\beta$-cell vagally mediated insulin release (autonomic imbalance), leading to insulin hypersecretion, weight gain, and consequent IR. Different reports have showed that this phenomenon can be suppressed by pancreatic vagotomy, as well as reverted by octreotide administration, which prevent insulin hypersecretion (57) (Figure 3). Similarly described in ALL survivors, additional mechanisms implicated in weight gain in brain tumor survivors are, as follows: lack of sensitivity to endogenous leptin (due to hypothalamic damage), and physical inactivity $(39,58)$.

\section{OTHER CANCER GROUPS}

In addition to ALL and brain tumors, particularly craniopharyngiomas and those receiving high-dose cranial RT, other types of pediatric tumors have also been associated with the occurrence of obesity (particularly visceral obesity), as well as other features of the MetS, as follows: sarcomas, lymphomas, disseminated testicular cancer, neuroblastomas, Wilms tumor, and following BMT (1-9). In the following lines, we will concentrate on sarcomas and BMT.

So far, male visceral abdominal obesity, and an increased prevalence of MetS traits, comprising hypertension, and hypertriglyceridemia, has been described in pediatric sarcoma survivors (predominantly Ewings), treated with multi-agent CT, with or without RT. However, no association between GH deficiency and the occurrence of MetS traits was observed. Physical inactivity due to altered ambulatory function, a consequence of surgical resection and/or RT to trunk, pelvic and lower extremity may also contribute for the development of obesity in pediatric sarcoma survivors (9).

Currently, it is becoming clear from a number of studies among adult and pediatric recipients of BMT that they are also at risk of developing abdominal adiposity, IR and other features of MetS, such as impaired glucose tolerance, T2DM, dyslipidemia, and hypertension $(5,7,59,60)$. Total body irradiation (TBI), untreated hypogonadism, and abdominal adiposity (a known feature of GH deficiency) were considered risk 


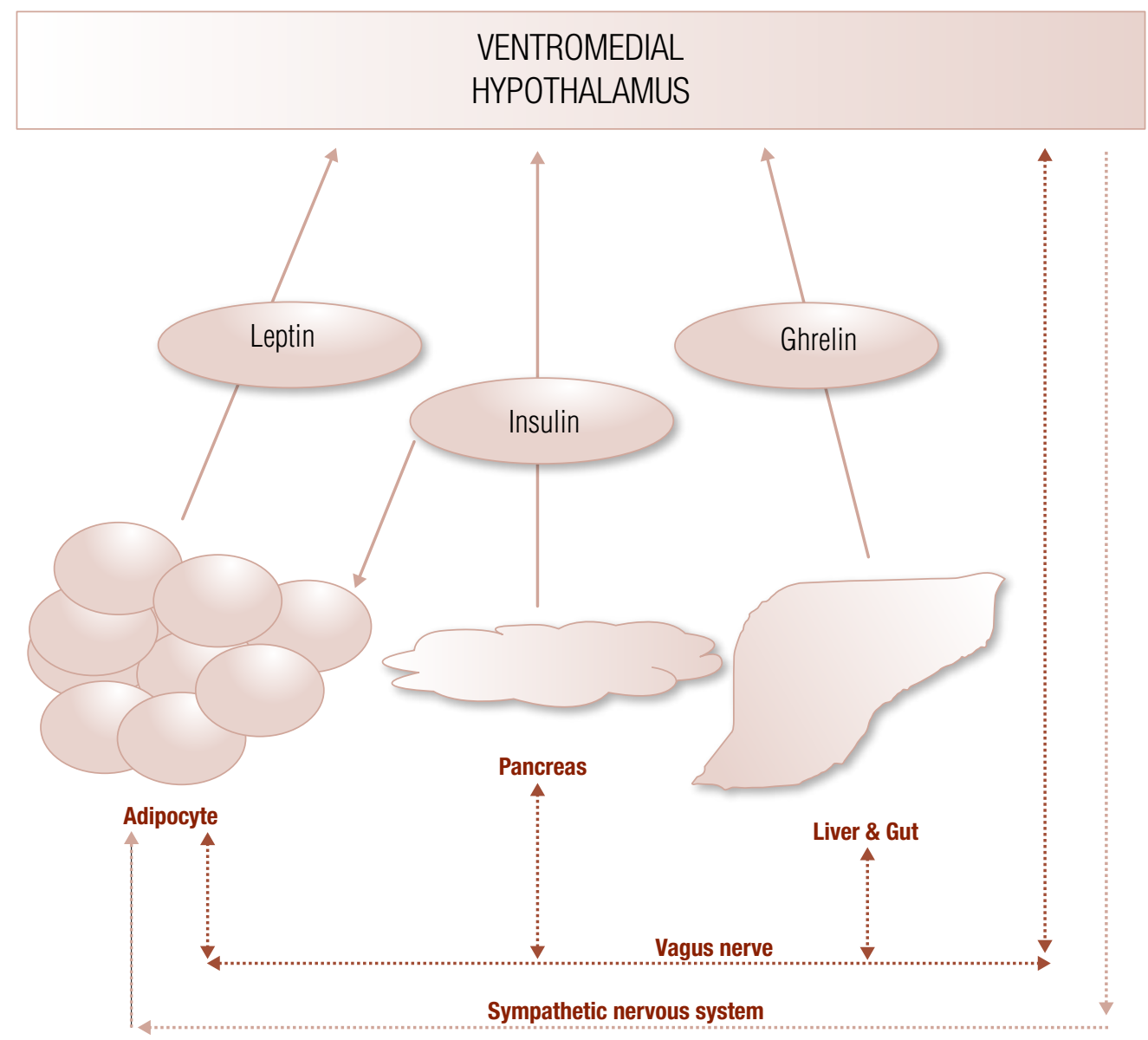

Figure 3. Schematic representation of the interaction between the ventromedial hypothalamus (VMH) and peripheral signals leading to vagally mediated hyperinsulinemia in brain tumor survivors (hypothalamic obesity).

Afferent vagal and hormonal signals are generated from the liver, gut, pancreas, and adipocytes, and are interpreted in the VMH. Efferent signals from the VMH in turn stimulate either the adipocytes through sympathetic nervous system to enhance lipolysis or the vagus nerve to increase insulin secretion, with resultant adipogenesis. When there is a lesion of the VMH, it results in dysregulation of pancreatic $\beta$-cell vagally mediated insulin release, leading to insulin hypersecretion, weight gain, and consequent IR (Adapted from reference 57).

factors for the development of hyperinsulinemia, impaired glucose tolerance, and T2DM in pubertal and adult survivors, having TBI the strongest association (5). Nonetheless, the mechanisms underlying this still remain unclear, and to date the effect of TBI on the function of adipose tissue in secreting adipokines has not been studied yet $(5,60)$.

\section{CONCLUSION REMARKS AND FUTURE ISSUES}

The prevalence and pathogenesis of obesity, particularly visceral adiposity, and MetS in long-term survivors of cancer, their significance, as well as the relationship between these factors and the development of CVD after cancer treatment have yet to be clarified. Weight gain, especially in some specific cancer groups predis- posing to MetS traits, must encourage a more active lifestyle during the first years of therapy, particularly in ALL and brain tumor individuals.

Rapid weight gain in infancy may be a risk factor for later adiposity. Early infancy may provide an opportunity for interventions aimed at reducing later obesity risk. Additionally, research should focus on understanding the underlying biologic and physiological basis of sexspecific and genetic-determined risks (polymorphisms). Current nutritional strategies that promote catch-up growth should include some monitoring of adiposity.

Hypothalamic obesity often results in devastating metabolic and psychosocial complications, requiring provision of dietary and behavioral modifications, encouragement of regular physical activity, psychological counseling, as well as antiobesity drugs. 
Further research is still necessary to define the epidemiology, risk factors, and mechanisms behind the development of overweight and metabolic disorders in survivors of pediatric cancers. Longitudinal prospective studies are still necessary to estimate actual prevalence and facilitate the unravelling of the underlying mechanisms in change of body distribution rather than composition, and the relationship between adiposity and hormonal regulation. Recommendations for future research also include exploring ways to assess visceral adiposity, to identify better biochemical markers for prediction of disease progression, including $\operatorname{PPAR} \gamma$, and insulin, and to effectively prevent visceral obesity as a MetS trait in youth.

Acknowledgements: This work was supported by grants from the Fundaçao de Amparo a Pesquisa do Estado de Sao Paulo (Fapesp) (06/06162-9 to G. G-J).

Disclosure: No potential conflict of interest relevant to this article was reported.

\section{REFERENCES}

1. Oeffinger KC, Buchanan GR, Eshelman DA, Denke MA, Andrews TC, Germak JA, et al. Cardiovascular risk factors in young adult survivors of childhood acute lymphoblastic leukemia. J Pediatr Hematol/Oncol. 2001;23(7):424-30.

2. Heikens J, Ubbink MC, Van der Pal HPJ, Bakker PJ, Fliers E, Smilde TJ, et al. Long term survivors of childhood brain cancer have an increased risk for cardiovascular disease. Cancer. 2000;88(9):2116-21.

3. Link K, Moëll C, Garwicz S, Cavallin-Ståhl E, Björk J, Thilén U, et al. Growth hormone deficiency predicts cardiovascular risk in young adults treated for acute lymphoblastic leukemia in childhood. J Clin Endocrinol Metab. 2004;89(10):5003-12.

4. Gurney JG, Ness KK, Sibley SD, O'Leary M, Dengel DR, Lee JM, et al. Metabolic syndrome and growth hormone deficiency in adult survivors of childhood acute lymphoblastic leukemia. Cancer. 2006;107(6):1303-12.

5. Neville KA, Cohn RJ, Steinbeck KS, Johnston K, Walker JL. Hyperinsulinemia, impaired glucose tolerance, and diabetes mellitus in survivors of childhood cancer: prevalence and risk factors. J Clin Endocrinol Metab. 2006;91(11):4401-7.

6. Janiszewski PM, Oeffinger KC, Church TS, Dunn AL, Eshelman $\mathrm{DA}$, Victor RG, et al. Abdominal obesity, liver fat, and muscle composition in survivors of childhood acute lymphoblastic leukemia. J Clin Endocrinol Metab. 2007;92(10):3816-21.

7. Taskinen M, Lipsanen-Nyman M, Tiitinen A, Hovi L, SaarinenPihkala UM. Insufficient growth hormone secretion is associated with metabolic syndrome after allogeneic stem cell transplantation in childhood. J Pediatr Hematol/Oncol. 2007;29(8):529-34.

8. Trimis G, Moschovi M, Papassotiriou I, Chrousos G, TzortzatouStathopoulou F. Early indicators of dysmetabolic syndrome in young survivors of acute lymphoblastic leukemia in childhood as a target for preventing disease. J Ped Hematol/Oncol. 2007;29(5):309-14.

9. Hoffman KE, Derdak J, Bernstein D, Reynolds JC, Avila NA, Gerber $\mathrm{L}$, et al. Metabolic syndrome traits in long-term survivors of pediatric sarcoma. Pediatr Blood Cancer. 2008;50(2):341-6.
10. Oeffinger KC. Are survivors of acute lymphoblastic leukemia (ALL) at increased risk of cardiovascular disease? Pediatr Blood Cancer. 2008;50 (2 Suppl):462-7.

11. Oeffinger KC, Mertens AC, Sklar CA, Yasui Y, Fears T, Stovall M, et al. Obesity in adult survivors of childhood acute lymphoblastic leukemia: a report from the Childhood Cancer Survivor Study. J Clin Oncol. 2003;21(7):1359-65.

12. Garmey EG, Liu Q, Sklar CA, Meacham LR, Mertens AC, Stovall $M A$, et al. Longitudinal changes in obesity and body mass index among adult survivors of childhood acute lymphoblastic leukemia: a report from the Childhood Cancer Survivor Study. J Clin Oncol. 2008;26(28):4639-45.

13. Sklar CA, Mertens AC, Walter A, Mitchell D, Nesbit ME, O'Leary $M$, et al. Changes in body mass index and prevalence of overweight in survivors of childhood acute lymphoblastic leukemia: role of cranial irradiation. Med Pediatr Oncol. 2000;35(2):91-5.

14. Dalton VK, Rue M, Silverman LB, Gelber RD, Asselin BL, Barr $\mathrm{RD}$, et al. Height and weight in children treated for acute lymphoblastic leukemia: relationship to CNS treatment. J Clin Oncol. 2003;21(15):2953-60.

15. Brouwer CA, Gietema JA, Kamps WA, de Vries EG, Postma A. Changes in body composition after childhood cancer treatment: impact on future health status - a review. Crit Rev Oncol Hematol. 2007;63(1):32-46.

16. Argüelles B, Barrios V, Buño M, Madero L, Argente J. Anthropometric parameters and their relationship to serum growth hormone-binding protein and leptin levels in children with acute lymphoblastic leukemia: a prospective study. Eur J Endocrinol. 2000;143(2):243-50.

17. Adan L, Trivin C, Sainte-Rose C, Zucker JM, Hartmann O, Brauner $R$. GH deficiency caused by cranial irradiation during childhood: factors and markers in young adults. J Clin Endocrinol Metab. 2001;86(11):5245-51.

18. Siviero-Miachon AA, Spinola-Castro AM, Tosta-Hernandez PDC, de Martino Lee ML, Petrilli AS. Leptin assessment in acute lymphocytic leukemia survivors: role of cranial radiotherapy? J Ped Hematol/Oncol. 2007;29(11):776-82.

19. Brennan BMD, Rahim A, Blum WF, Adams JA, Eden OB, Shalet $\mathrm{SM}$. Hyperleptinaemia in young adults following cranial irradiation in childhood: growth hormone deficiency or leptin insensitivity? Clin Endocrinol (Oxf). 1999;50(2):163-9.

20. Siviero-Miachon AA, Spinola-Castro AM, Guerra-Junior G. Detection of metabolic syndrome features among childhood cancer survivors: a target to prevent disease. Vasc Health Risk Manag. 2008;4(4):825-36.

21. Krassas GE, Tzotzas T. Do obese children become obese adults: childhood predictors of adult disease. Pediatr Endocrinol Rev. 2004; 1 (Suppl 3):455-9.

22. Dekkers JC, Podolsky RH, Treiber FA, Barbeau P, Gutin B, Snieder $H$. Development of general and central obesity from childhood into early adulthood in African American and European American males and females with a family history of cardiovascular disease. Am J Clin Nutr. 2004;79(4):661-8.

23. Renehan AG, Roberts DL, Dive C. Obesity and cancer: pathophysiological and biological mechanisms. Arch Physiol Biochem. 2008;114(1):71-83.

24. Harish K, Dharmalingam M, Himanshu M. Study protocol: insulin and its role in cancer. BMC Endocr Disord. 2007;7:10.

25. Ben-Shlomo Y, Holly J, McCarthy A, Savage P, Davies D, Gunnell $D$, et al. An investigation of fetal, postnatal and childhood growth with insulin-like growth factor I and binding protein 3 in adulthood. Clin Endocrinol (Oxf). 2003;59(3):366-73.

26. Spinola-Castro AM, Siviero-Miachon AA, Guerra-Junior G, Geloneze-Neto $B$. Insulin resistance in childhood cancer survivors: a link between metabolic syndrome features. In: Yao EB, editors. 
Insulin Resistance: New Research. 1. ed. New York: Nova Science Publishers, Inc. 2009 1st quarter [announcing].

27. Zhou JR, Blackburn GL, Walker WA. Symposium introduction: metabolic syndrome and the onset of cancer. Am J Clin Nutr. 2007;86(3):S817-9.

28. Frasca F, Pandini G, Sciacca L, Pezzino V, Squatrito S, Belfiore A, et al. The role of insulin receptors and IGF-I receptors in cancer and other diseases. Arch Physiol Biochem. 2008;114(1):23-37.

29. Goodman HM. Hormonal regulation of fuel metabolism. In: $\mathrm{H}$. Maurice Goodman, editors. Basic Medical Endocrinology, 4th ed. Academic Press, Elsevier Ltd. 2008. p. 151-74.

30. Tontonoz P, Spiegelman BM. Fat and beyond: the diverse biology of PPARgamma. Annu Rev Biochem. 2008;77:289-312.

31. Shoelson SE, Lee J, Goldfine AB. Inflammation and insulin resistance. J Clin Invest. 2006;116(7):1793-801.

32. Wang $T$, Xu J, Yu X, Yang R, Han ZC. Peroxisome proliferatoractivated receptor gamma in malignant diseases. Crit Rev Oncol Hematol. 2006;58(1):1-14.

33. Chow EJ, Friedman DL, Yasui Y, Whitton JA, Stovall M, Robison $\mathrm{LL}$, et al. Decreased adult height in survivors of childhood acute lymphoblastic leukemia: a report from the Childhood Cancer Survivor Study. J Pediatr. 2007;150(4):370-5.

34. Gurney JG, Ness KK, Stovall M, Wolden S, Punyko JA, Neglia JP, et al. Final height and body mass index among adult survivors of childhood brain cancer: Childhood Cancer Survivor Study. J Clin Endocrinol Metab. 2003;88(10):4731-9.

35. Reilly JJ, Kelly A, Ness P, Dorosty AR, Wallace WH, Gibson BE, et al. Premature adiposity rebound in children treated for acute lymphoblastic leukemia. J Clin Endocrinol Metab. 2001;86(6):2775-8.

36. Nathan PC, Jovcevska V, Ness KK, Mammone D'Agostino N, Staneland $\mathrm{P}$, Urbach $\mathrm{SL}$, et al. The prevalence of overweight and obesity in pediatric survivors of cancer. J Pediatr. 2006;149(6):518-25.

37. Ross JA, Oeffinger KC, Davies SM, Mertens AC, Langer EK, KiffmeyerWR, et al. Genetic variation in the leptin receptor gene and obesity in survivors of childhood acute lymphoblastic leukemia: a report from the Childhood Cancer Survivor Study. J Clin Oncol. 2004;22(17):3558-62.

38. Asner S, Ammann RA, Ozsahin H, Beck-Popovic M, von der Weid NX. Obesity in long-term survivors of childhood acute lymphoblastic leukemia. Pediatr Blood Cancer. 2008;51(1):118-22.

39. Harz KJ, Müller HL, Waldeck E, Pudel V, Roth C. Obesity in patients with craniopharyngioma: assessment of food intake and movement counts indicating physical activity. J Clin Endocrinol Metab. 2003;88(11):5227-31.

40. Jarfelt M, Lannering B, Bosaeus I, Johannsson G, Bjarnason R. Body composition in young adult survivors of childhood acute lymphoblastic leukaemia. Eur J Endocrinol. 2005;153(1):81-9.

41. Lee S, Bacha F, Gungor N, Arslanian SA. Waist circumference is an independent predictor of insulin resistance in black and white youths. J Pediatr. 2006;148(2):188-94.

42. Zimmet P, Alberti G, Kaufman F, Tajima N, Silink M, Arslanian S, et $\mathrm{al}$, on behalf of the International Diabetes Federation Task Force on Epidemiology and Prevention of Diabetes. The metabolic syndrome in children and adolescents. Lancet. 2007;369(9579):2059-61.

43. Arif $\mathrm{H}$, Racette SB, Villareal DT, Holloszy JO, Weiss EP. Comparison of methods for assessing abdominal adipose tissue from magnetic resonance images. Obesity (Silver Spring). 2007;15(9):2240-4.
44. Kourti M, Tragiannidis A, Makedou A, Papageorgiou T, Rousso I, Athanassiadou F. Metabolic syndrome in children and adolescents with acute lymphoblastic leukemia after the completion of chemotherapy. J Pediatr Hematol/Oncol. 2005;27(9):499-501.

45. Papadia C, Naves LA, Costa SS, Vaz JA, Domingues L, Casulari LA. Incidence of obesity does not appear to be increased after treatment of acute lymphoblastic leukemia in Brazilian children: role of leptin, insulin, and IGF-1. Horm Res. 2007;68(4):164-70.

46. Talvensaari KK, Lanning M, Tapanainen $P$, Knip M. Long-term survivors of childhood cancer have an increased risk of manifesting the metabolic syndrome. J Clin Endocrinol Metab. 1996;81(8):3051-5

47. Campfield LA, Smith FJ, GuisezY, Devos R, Burn P. Recombinant mouse OB protein: Evidence for a peripheral signal linking adiposity and central neural networks. Science. 1995;269(5223):546-9.

48. Hino M, Nakao T, Yamane T, Ohta K, Takubo T, Tatsumi N. Leptin receptor and leukemia. Leuk Lymphoma. 2000;36(5-6):457-61.

49. Birkebaek NH, Fisker S, Clausen N, Tuovinen V, Sindet-Pedersen $\mathrm{S}$, Christiansen JS. Growth and endocrinological disorders up to 21 years after treatment for acute lymphoblastic leukemia in childhood. Med Pediatr Oncol. 1998;30(6):351-6.

50. Blum WF, Englaro P, Hanitsch S, Juul A, Hertel NT, Müller J, et al. Plasma leptin levels in healthy children and adolescents: dependence on body mass index, body fat mass, gender, pubertal stage, and testosterone. J Clin Endocrinol Metab. 1997;82(9):2904-10.

51. Williams SM. Weight and height growth rate and the timing of adiposity rebound. Obes Res. 2005;13(6):1123-30.

52. Ibáñez L, Ong K, Dunger DB, de Zegher F. Early development of adiposity and insulin resistance after catch-up weight gain in small-for-gestational-age children. J Clin Endocrinol Metab. 2006;91(6):2153-8

53. Wong SC, Ng SM, Didi M. Children with congenital hypothyroidism are at risk of adult obesity due to early adiposity rebound. Clin Endocrinol (Oxf). 2004;61(4):441-6.

54. Srinivasan S, Ogle GD, Garnett SP, Briody JN, Lee JW, Cowell CT. Features of the metabolic syndrome after childhood craniopharyngioma. J Clin Endocrinol Metab. 2004;89(1):81-6.

55. Lustig RH, Post SR, Srivannaboon K, Rose SR, Danish RK, Burghen $\mathrm{GA}$, et al. Risk factors for the development of obesity in children surviving brain tumors. J Clin Endocrinol Metab. 2003;88(2):611-6.

56. Ahmet A, Blaser S, Stephens D, Guger S, Rutkas JT, Hamilton J. Weight gain in craniopharyngioma - a model for hypothalamic obesity. J Pediatr Endocrinol Metab. 2006;19(2):121-7.

57. Lustig RH. Autonomic dysfunction of the $\beta$-Cell and the pathogenesis of obesity. Rev Endocr Metab Disord. 2003;4(1):23-32.

58. Roth C, Wilken B, Hanefeld F, Schröter W, Leonhardt U. Hyperphagia in children with craniopharyngioma is associated with hyperleptinaemia and a failure in the downregulation of appetite. Eur J Endocrinol. 1998;138(1):89-91.

59. Shalitin S, Phillip M, Stein J, Goshen Y, Carmi D, Yaniv I. Endocrine dysfunction and parameters of the metabolic syndrome after bone marrow transplantation during childhood and adolescence. Bone Marrow Transplant. 2006;37(12):1109-17.

60. Baker KS, Ness KK, Steinberger J, Carter A, Francisco L, Burns LJ, et al. Diabetes, hypertension, and cardiovascular events in survivors of hematopoietic cell transplantation: a report from the Bone MarrowTransplantation Survivor Study. Blood. 2007;109 (4):1765-72. 